\title{
An Analysis of the Development of Cryptocurrency Research
}

\author{
Shaen Corbet $^{a, b *}$, Brian Lucey $^{c}$ \\ ${ }^{a}$ DCU Business School, Dublin City University, Dublin 9, Ireland \\ ${ }^{b}$ School of Accounting, Finance and Economics, University of Waikato, New Zealand \\ ${ }^{c}$ Trinity Business School, Trinity College Dublin, Dublin 2 \& \\ University of Sydney Business School, University of Sydney, Darlington, NSW, Australia \\ *Corresponding Author: shaen.corbet@dcu.ie
}

\begin{abstract}
In this chapter, we investigate the literature on both broad- and narrow-based cryptocurrency research from a bibliometric and scientometric perspective. While Bitcoin, presented as the first every cryptocurrency by Nakamoto [2009], was established as the first piece of a decade-long expansion of academic literature based on the development of this new financial product and the associated benefits and issues contained therein. We attempt to re-trace and provide a thorough explanation of the flow of research direction during this period across all disciplines. We provide clear evidence of a growing but fragmented research area. We conclude that there is a significant difference in how researchers treat broad conceptual topics versus individual products. We finally provide a concise overview of the current topics that have been central to recent research efforts, while attempting to provide oversight key areas that have presented evidence of particular deficiency. Such recommendations will provide direction for future research synergy.
\end{abstract}

Keywords: Bitcoin, Digital Currency, Cryptocurrency, Bibliometrics, Topic Modelling.

\section{Introduction}

The aim of this chapter is to provide a short overview of cryptocurrency research as of the end of 2019. We do this by means of a scientometric analysis, which has been used across a wide-ranging number of disciplines. We do not provide here a critical literature review per se. Rather, our ambition is to present the pathway through which research has flowed in the past decade. To do so we draw on similar pieces of work across other disciplines, such as that of sustainability and sustainability development (Olawumi and Chan [2018]), the development of building information systems (Zhao [2017], He et al. [2017]), food authentication (Danezis et al. [2016]), biotic identification (Ruaro and Gubiani [2013] and even at the level of products, such as algae, biohydrogen and biodiesel (Konur [2011, 2012a,b]). With regards to examples as to how such research can provide 
benefit to broad disciplines, Rotolo et al. [2015] developed a definition of 'emerging technologies' and linked the conceptual effort with the development of a framework for the operationalisation of technological emergence, which could then be used to trace the development of research over time. Serenko et al. [2010] conducted a meta-analysis of prior scientometric research of the knowledge management using 108 scientometric studies of the discipline and subjecting each meta-analysis techniques. Further, ? provides such a review as of early 2019, What we aim for here is to analyse the development of this area of research in terms of its intellectual structure. Lowry et al. [2013] investigated journal quality and the association for information systems, specifically analysing as to whether expert journal assessments add value? The authors conclude that bibliometric measures provide very similar results to expert-based methods in determining a tiered structure of IS journals, thereby suggesting that bibliometrics can be a complete, less expensive, and more efficient substitute for expert assessment.

The rapid development of cryptocurrencies as a financial product appears to have taken many regulatory systems by surprise. While research to uncover the many systemic repercussions of this digital finance evolution continues to expand at pace, much evidence points toward substantially differing characteristics associated with these new financial products relative to traditional financial products on which much regulation has been honed over time. The development of cryptocurrencies and the surrounding research associated at both the narrow-product level (namely, Bitcoin or Ethereum individually) or at the broad-level (all cryptocurrencies) has been further advertised by the unprecedented price appreciations that have taken place across a number of assets, particularly that of Bitcoin. These products have therefore offered substantial opportunities to a number of speculative investors, not to mention a transmission vehicle through which those with illicit needs can take advantage of regulatory circumvention. Research, beginning with such humble beginnings through the work of Nakamoto [2009] has expanded to analyse technical, sociological, legal, financial and economical aspects of the product. However, such research has recently begun to question if this price evolution could be a symptom of other deeper issues such as the presence of financial bubbles (Corbet et al. [2018]; Fry [2018]), or as to whether the product is now unfortunately overcome with illegality. In recent works to identify such illicit tactics, Griffins and Shams [2018] investigated Tether's influence in Bitcoin and other cryptocurrency prices to find that purchases with Tether were timed following market downturns and resulted in significant increases in the price of Bitcoin. Further, less than 1\% of the hours in which Tether experienced significant transactions is associated with $50 \%$ of the increase in Bitcoin prices and $64 \%$ of other top cryptocurrencies, drawing the damning conclusion that Tether was used to provide price support and manipulate cryptocurrency prices. Along with this source of instability, cryptocurrency exchanges as well as individual currencies have experienced several sophisticated hacking events, further damaging the confidence in this asset class. Further, Gandal et al. [2018] identified the impact of suspicious trading activity on the Mt.Gox Bitcoin exchange theft, when approximately 600,000 Bitcoins were 
attained. The authors demonstrated that the suspicious trading likely caused the spike in price in late 2013 from $\$ 150$ to $\$ 1,000$, most likely driven by one single actor. These two significant pieces of research have fine-tuned the focus of regulators, policy-makers, and academics alike, as the future growth of cryptocurrencies cannot be sustained at pace with such significant questions of abnormality remaining unanswered.

This chapter focuses distinctly on the pathway that such cryptocurrency research has taken. Further, we attempt to provide oversight of the key areas that appear to have been under-resourced with academic coverage and as to where we observe current trends to be focused. The rest of the chapter is as follows: in Section 2 we provide a very short review of the key developments in cryptocurrency research to date. In Section 3 we explain the data and methodologies used to analyse the research and carry out the bibliometric analysis. In Section 4 we provide the results of this analysis, while in Section 5 we conclude.

\section{The development of cryptocurrency research: A very short review}

Since the product's evolution through the work of Nakamoto [2009], Bitcoin has developed as an investment asset that have no association with any higher authority, specific country, tangible asset or firm, and the value of it is based on the security of an algorithm which is able to trace all transaction (Corbet et al. [2020]). Corbet et al. [2019] provided a thorough overview of the empirical literature based on the major topics that have been associated with the market for cryptocurrencies since their development as a financial asset. Anonymity and decentralisation of cryptocurrency attracted attention from both users and investors, which caused enormous growth of market capitalisation and price of Bitcoin. Corbet et al. [2018] while utilising the bubble identification methodology of Phillips et al. [2011], found clear evidence of periods in which Bitcoin and Ethereum were experiencing bubble phases. Urquhart [2016a] investigated the efficiency of Bitcoin using a battery of robustness tests to find that returns are significantly inefficient over their selected full sample, but when dividing the same sample, Bitcoin presented evidence of becoming more efficient. Recent findings by Sensoy [2018] also report that Bitcoin prices both in terms US dollar and euros have become more efficient. Similar research has been conducted on the newly developed Bitcoin futures market (Corbet et al. [2018]; Katsiampa et al. [2019a]; Katsiampa et al. [2019b]). Further research areas have developed with focus on trading rules (Corbet et al. [2019]); portfolio design (Akhtaruzzaman et al. [2019]); the creation of derivatives product exchanges (Akyildirim et al. [2019]); implied volatility (Akyildirim et al. [2019]); and market cross-correlations and interactive dynamics (Akyildirim et al. [2019], Corbet et al. [2018, 2019])

In Table 1 we observe the descriptive statistics for the data used in this bibliometric analysis using all available between the first observation, identified as the work of Nakamoto [2009] until that of November 2019. The research is separated between two distinct types, firstly, that relating 
to a digital currency directly, such as Bitcoin for example, and secondly, broad coverage of cryptocurrencies as a research topic. Figure 1 presents evidence of the dramatic growth in research based on this new product during the time analysed. We clearly observe that research surrounding individual products account for approximately twice that of broad cryptocurrency research. There are 521 separate sources of coverage for research by product, however, only 323 sources for that relating to the sector. With regards to citations, product-level research focused on 10,773 other pieces of work, while topic-level research accounted for 3,739 citations, however, product-level research has generated 9.22 cites per document while topic-wide research generated 6.99. There is evidence of increased multi-authorship on topic-level research, with an average of 2.65 authors per paper, substantially above the average of 1.99 for product-level research. To date, 3,742 authors have worked on research relating to cryptocurrencies whether narrow or broad,

\section{Insert Table 1 and Figure 1 about here}

In Table 2 we observe the top citations sources by author as ranked by the number of articles and associated fractional citations. In terms of both narrow and broad areas of research, we can identify a number of authors that are prevalent across both research-types. In Table 3 we observe the top citations across countries based by both narrow and broad research types. In terms of narrow-based research, we observe that the United States have produced, to this point, the largest number of research articles, however, in terms of quality, measured by the number of citations, the UK possesses a far more substantial level of cites per article (12.5) in comparison to the United States (7.2). Both Lebanon and Switzerland possess the largest number of cites per article, but these estimates are provided with the caveat of quite a low number of articles published (13 and 14 respectively). Considering broad-based research, China has provided far more research articles. Again, the UK stands out through the possession of a considerable number of cites per article, considering the substantial number of research papers that have been published. However, both Ireland and Lebanon lead the way in terms of citations per article (27.8 and 17.7 respectively).

\section{Insert Tables 2 and 3 about here}

In Table 4, we observe the top journals in terms of research output and citations. In terms of both narrow and broad types of research, Finance Research Letters has published the largest number of papers and is closely followed by Economics Letters, who possess are larger number of citations in both categories. Both of these journals are closely followed by Applied Economics Letters and IEEE Access. It becomes quickly evident that the letters-format of research appears to be most popular amongst cryptocurrency researchers. This is most likely due to the fast-moving nature of the research area and the ability to quickly disseminate research in a reputable and visible 
manner. Applied Economics, Future Generation Computer Systems and International Review of Financial Analysis are journals that would be considered to produce more substantial pieces or work closely these short-form research outputs. There also appears to be quite a coherent grouping of computer-based research outputs along with both economics and finance-based research outputs.

\section{Insert Tables 4 through 6 about here}

The top articles as defined by citations, as per late-2019 are presented in Table 5 . In terms of citations, Tschorsch and Scheuermann [2016] had produced the most cited paper in terms of narrowfocused cryptocurrency research, providing a technical survey of decentralised digital currencies in the IEEE Communications Surveys \& Tutorials. With regards to broad-based cryptocurrency research, Li et al. [2017] produced a survey on the security of blockchain systems in the journal Future Generation Computer Systems. While much of this research focuses specifically on the technical elements of Bitcoin and cryptocurrency at large, some of the most well known pieces of research relating directly to economics and finance research include that of Cheah and Fry [2015] who provided an empirical investigation into the fundamental value of Bitcoin; Bouri et al. [2017] who investigated as to whether Bitcoin was a diversifier through its hedge and safe-haven properties; and Urquhart [2016b] who analysed Bitcoin in terms of its efficiency as a product. Research from Economics Letters and Finance Research Letters appear to be most pronounced. This is further supported in Table 6 where we observe the combined number of cryptocurrencybased research citations (inclusive of both broad- and narrow-based research). In terms of broad citations, Economics Letters is the most visible research outlet with 1,269 citations, but this is closely followed by both Finance Research Letters and Physica A. Then follows International Review of Financial Analysis, PLOS One, Applied Economics, Applied Economic Letters and Econometrica. We can clearly observe broad cross-discipline coverage, with research spanning economics, finance, physics, communications, technological, sociological and econometric-based topics.

\section{Data selection and methods}

\subsection{Methods}

Bibliometrics, the analysis of citation and author networks, as well as its close relative scientometrics, have had significant traction in areas outside finance. In the life sciences, medicine and nursing especially, Cochrane Reviews, deep systemic reviews of an area incorporating meta analyses and bibliometrics, are seen as the gold standard for evidence. A search for "bibliometrics or scientometrics" in Scopus will show that close to a quarter of all papers in this area are in Medicine. The next largest lies in Library and Archival science. In the UK the 2021 Research Evaluation Framework reference documents suggest that bibliometrics will be a major and indeed enhanced 
component in both suggested submission strategies and in how the review panels form judgements ${ }^{1}$ More critically, Jappe et al. [2018] provides a (Sociologically focused) overview of the influence of bibliometrics and scientometrics on research evaluation and funding bodies. Levine-Clark and Gil [2008],Vieira and Gomes [2009], Franceschet [2010] and Mongeon and Paul-Hus [2016a] - which concludes that each has advantages but all should, ideally, be used. Considerable data cleaning would be required however to create a blended database of all. In addition, not all meta data are present in all three data bases, in particular Google Scholar ${ }^{2}$.

Core bibliometric approaches involve surfacing the linkages between papers or articles. Here we use, unless otherwise indicated, the number of articles to weight collaboration and linkage. Thus linkages are stronger when say two authors collaborate with each other on 10 papers than would be the case where another two authors collaborate on 5. These linkages lend themselves nicely to graphical presentation, being in essence network models. Graphic models rely on nodes and edges (See Kosnik [2018]) where the nodes here are determined by the individual units of analysis (authors, countries etc) and the edges the linkages between them. In all cases we apply fractional counting, whereby authorship or nationality among other characteristics are scaled to the number of occurrences. Therefore an author appearing in a paper with five others has their linkages weighted $\frac{1}{6}$. Linkages are, unless otherwise noted, based on number of documents. The thicker the connecting lines in the networks the higher the weight. The package VosViewer was used for this analysis, supplemented by Gephi ${ }^{3}$ and the R package Bibliometrix ${ }^{4}$ (Aria and Cuccurullo [2017].

\subsection{Data}

We use the Scopus database as our source of record. For the analysis in this paper all data are sourced from Scopus, as this captures the widest range of papers with complete reference sets and author/institution metadata in a consistent form. From the authors knowledge of the area we are confident that no significant academic source of papers was omitted. We chose 1990 as a starting point for the research as the further back in any bibliometric database one goes the more scant becomes the coverage. This issue is discussed in Michels and Schmoch [2012] and in Harzing and Alakangas [2016]. Finally, all citation measures, unless otherwise noted, are inclusive of self citation. Waltman [2016], S5.3, contains an extensive discussion of self citation and its effects on scientometric measures and analyses. The conclusion of this section is that in large scale analyses self citation does not overly bias or distort findings. Nor is there any clear finding that for authors, as opposed to say countries or institutions, self citation should pose a problem for scientometric

\footnotetext{
${ }^{1}$ See https://thebibliomagician.wordpress.com/2018/08/13/metrics-in-latest-ref-documents/ for a discussion and further linkages

${ }^{2}$ One issue with all databases, discussed in Mongeon and Paul-Hus [2016b] is that they tend to have an over representation of English language journals at the expense of others.

${ }^{3}$ for analysis of centrality measures and checking of the consistency of the graphs generated from Vosviewer

${ }^{4}$ for preliminary data analysis and measures of author and country dominance
} 
analysis, overall. We break out our analyses into two categories, narrow product based research, examining individual cryptocurrencies, and broader area based research looking at the entirety of the research

As per Corbet et al. [2019], we further estimate the applicability of Lotka's Law (Chung and Cox [1990]) to the dataset. Lotka's law suggests that the number of publication by authors is best described as an inverse square law. Lotka's Law is formulated as $A=K / X^{n}$, where $K$ and $n$ are constants. Usually $n=2$ is the number of authors publishing $n$ papers and $X$ represents the number publishing one paper. This implies that the number of authors publishing $X$ number of articles is a fixed ratio, 2, to the number of authors publishing a single article. We used the $\mathrm{R}$ package Bibliometrix (Aria and Cuccurullo [2017] for this analysis. The search strategy used for the broad-based analysis was:

(TITLE-ABS-KEY(cryptocurrency OR cryptocurrencies...)

(TITLE-ABS-KEY(...OR digital currency OR digital currencies)

AND PUBYEAR $>2010$

AND(LIMIT-TO(DOCTYPE,"ar"))

AND(LIMIT-TO (SUBJAREA,"ECON" OR "FIN"))

AND(EXCLUDE(PREFNAMEAUID,"UndefinedUndefined"))

While the search strategy used for the narrow-based analysis was:

$$
\begin{aligned}
& \text { (TITLE-ABS-KEY(Bitcoin OR Ethereum OR Litecoin) } \\
& \text { AND PUBYEAR > } 2010 \\
& \text { AND(LIMIT-TO(DOCTYPE,"ar")) } \\
& \text { AND(LIMIT-TO (SUBJAREA,"ECON" OR "FIN")) } \\
& \text { AND(EXCLUDE(PREFNAMEAUID,"UndefinedUndefined")) }
\end{aligned}
$$

The last two exclusions were required due to large numbers of papers being returned which were opinion or reportage from The Economist Newspaper, classified as articles by Scopus. All data were downloaded as both CSV and as plaintext, where all information was selected. This allows for the analysis of inward and outward citations, of abstracts and of a wide variety of other bibliometric areas. The usage of the terms "cryptocurrency", "cryptocurrencies", "digital currency" and "digital currencies" enabled the analysis of broad-based cryptocurrency research. While the search of terms relating to "Bitcoin", "Ethereum" and "Litecoin" enabled a search of more narrow-focused product level research. 


\section{Results}

So what do we find when we examine research in economics and finance as it pertains to cryptocurrencies?

We first note a great rise in the numbers of articles, whether broad based or more narrowly based, with the great bulk arriving in the 2018-9 period. This is a very new area. A google trends search of Cryptocurrency or cryptocurrencies will illustrate this, with essentially no searches until early 2017. This is of course not surprising given that the Bitcoin ledger did not open until 2009. However, what is notable is the very significant uptick in research from 2017 to 2018, matching the rise in the Bitcoin price when the notion of such currencies really began to penetrate into the public and apparently the academic conscience.

We also evaluated the bibliometrics, per se, of the papers. Core bibliometric approaches involve surfacing the linkages between papers or articles. These linkages lend themselves nicely to graphical presentation, being in essence network models. In all cases we apply fractional counting, whereby authorship or nationality etc is scaled to the number of occurrences. Therefore an author appearing in a paper with five others has their linkages weighted $\frac{1}{6}$. Linkages are, unless otherwise noted, based on number of documents. The thicker the connecting lines in the networks the higher the weight, documents generally. The package VosViewer was used for this analysis.

\section{Insert Figure 2 about here}

First we examine, in Fig 2 the nature of coauthorship. This allows us to look into who is working with whom. Figure 2 positions this in terms of national collaboration. We split this into three lobes: narrow products in (a), broad areas in (b) and overall in (c) The size of the nodes indicates the number of units, documents here, while the thickness of the lines indicates the strength of the linkages. Colours and shades represent clusters based on linkages and collaboration. Starting at (c) we see four main lobes of collaborative research, one each centred on the UK, the USA, France and Spain. US based authors collaborate strongly with China, surprising perhaps given the restrictions on Cryptocurrencies in place in China. The UK grouping is essentially Europe, with Germany, Ireland And Russia well represented. Australia is also present in this grouping, as is Poland and Ukraine linked via Russia. The French grouping includes India and South Africa, while the Spanish group is more diffuse, with weaker links and a much more geographically spread nature. The broad product based network is much sparser, with three clusters, USA, UK and France based. The narrow product based research shows the four clusters, suggesting that first, collaboration in this area is "bottom up", focusing on products and specific instances of cryptocurrency, and second that this suggests a gap in exploiting broad conceptual areas. 
Examining individuals collaboration we see a very sparse network, regardless of how we cut the focus - there are islands of collaboration but these are archipelago in format. Enormous synergies exist in collaboration potential. The present authors appear as crucial nodes in a number of networks, but these are isolated, suggesting that we should ourselves practice what we preach!

\section{Insert Figures 3 and 4 about here}

In Figure 3 we observe a number of distinct research clusters based on both narrow and broad research. There is evidence of a number of clusters of authors that are prevalent across both types. This is also evident when considering the combination of both types of research, with further connections and segregation evident between these clusters and the topics on which each focus. Figure 4 shows a citation network of publishing sources. This is a network composed where we examine how often each element (here, journal or periodical) cites another. Again, the larger the node the more publications, the stronger the citation strength, the more often a source cites another, the thicker the linkage line. Also we again subdivide into networks, broad subject areas (b) and narrow product based research (a).

Overall a strong pattern of main players emerges. Clearly also there are two main clusters one is focused on the financial economics of the area, revolving around publications in Economics Letters, Finance Research Letters and International Review of Financial Analysis, while the other is a more technical cluster, with Physica A and computing journals. These are however intermingled. This is clearer in the broad area, with a third cluster emergent on law, security and commerce. Again there is a divergence between products and broad concerns. What seems evident is that collaborative opportunities for research do exist but also there is a degree of intellectual silo-ing here. There are very few citation linkages between the law/commerce/technical journals and the financial research journals.

\section{Insert Figure 5 about here}

We can deeper dive into the networks looking at cross national citation patterns. Shown in Figure 5 are two networks. The narrow based products show a very clear bilobal pattern. There is clear national segregation with the network of researchers from France and its satellites not really citing strongly the larger group of nations revolving around UK and USA. Why this is is unclear. The situation regarding broader areas of research is less polarised ; we see three lobes of more or less equal size and importance, one around China, one around the UK and one the USA, all with significant linkages each to the other. The inference is that when it comes to the broad architecture

of cryptocurrencies we see significant international intellectual cross pollination but not when it comes to applications. 


\section{Insert Figures 6 through 8 about here}

Shown in Figure 6 is a citation heatmap of articles published by country. The deeper the shade the more highly cited are these papers, normalised by the mean number of citations of all papers. We see that papers from France, Lebanon, USA, China and UK are highly cited despite, for example, Lebanon not being a major "source" of papers. So on what are authors working? In Figures 7 and 8 we see an analysis which surfaces this. In figure 7 we see an analysis of abstract words, while in 8 we see keywords. Each article requires authors to provide keywords when they submit a paper, usually up to 6. Shown in Figure 8 is a keyword cooccurance network. Again, as usual, the nodes of the network are the units of analysis, here either regular words in Figure 7, or keywords in Figure 8. The size is the relative frequency, the linkage thicknesses the number of times each are represented together. Examining first the abstract network, we notice four clear clusters. Three- computers (far right), economics (top left) and systems (bottom left) are each quite cohesive and also distinct from each other. There is a cluster linking these, but it is quite diffuse, which we can label Money. Not surprisingly this is at the centre of the entire network, these being cryptocurrencies after all. What is interesting is what is missing - there is no evidence here of a sustained research aim at cybercriminality, despite the concerns people have adduced since the start of the cryptocurrency era. No do we see a coherent cluster on environmental issues, nor on legal aspects. Overall the research community appears to be concerned with the technical, the financial aspects as well as with the technical aspects of designing the structures. This suggests that there exists, as much as we have seen earlier in author and country collaboration, great potential for "filling in the gaps" in research, through interdisciplinary research.

Specifically, when we turn our attention to the author provided keywords, in Figure 8, we see a different picture. Recall that the keywords are what the authors themselves believe best represent the material. As we have done before we split the analysis three ways: (a) shows products, (b) areas and (c) overall. For overall we see five clusters. From the right we see a cluster on the information structure of cryptocurrencies, one on security, then on the top one on design tolerances, a large cluster on the financial economics of cryptocurrencies and finally one that examines the microstructure and investment potential thereof. It is striking that we do not see this reflected in the abstracts - it suggests that what authors think, or wish for readers to think, they are examining is at variance with what is actually examined.

\section{Insert Figure 9 about here}

Figure 9 provides a similar analysis when we combine author keywords with the indexing keywords provided by the publishers, which are often the basis for bibliometric software such as Scopus 
or Web of Science to use. A further concept in scientometric analysis is that of bibliometric coupling. This refers to the degree of similarity which reference sets share. Think of two articles, each with say 20 references; in article A 5 each come from 4 other journals, in article B they come from 4 also but only 2 of the 4 are common. This set of two articles are coupled together by having common sources. However, if all references in each of the articles came from the same set of journals they would be more closely coupled. Thus we can construct a network where the linkages are the number of times that two journals are cited in common, the nodes are the journals themselves. This allows us to look at the extent to which research shares common roots or otherwise. Shown in Figure 10 through 11 is a representation of bibliometric coupling based on sources, that is to say seeing how often pools of research draw their references from the same journals. Figure 10 is for narrow product based research and Figure 11 for areas.

\section{Insert Figures 10 and 11 about here}

For narrow products we see two clusters; again a common theme in this research is that there tends to be islands of research with limited spillover. Researchers in products - Bitcoin, Ethereum etc - draw references and one can reasonably infer inspiration form either CS or financial economics literature but rarely from both. In CS the IEEE Access open access journal is dominant, followed bu PLOS One. It is interesting to see two open access journals as primary sources. In the larger and more diffuse economics and finance research cluster we see Finance Research Letters and Physica A as the dominant sources followed closely by Economics Letters. A marked preference is clear for shorter more focused papers in this area.

Focusing on broader areas as per Figure 11 we see four clusters of reference sources. The economics cluster has split into two - one centred around Physica A is a more quantitative orientated set, including Quantitative Finance and Econometrica, the other still centres on the letters journals. A third cluster now emerges, blending economy and technical issues, with no clear dominant source. The clusters are closer to each other in addition. A takeaway here might be that when it comes to conceptual areas researchers draw, as might be expected, from a wider and deeper well of primary sources than is the case for products. This is potentially problematic as products are embedded within the overall information and economic paradigms of their creation.

\section{Insert Figure 12 about here}

Finally in Figure 12 we see the evolution of the bibliometric coupling over time for products. In the top panel, we observe the clusters of research when analysing the period prior to 2015 . We observe scientific interest from PLOS One and Science, some interest from journals in economics and finance, such as Econometrica, and other areas such as computer science and environment. 
Interestingly, there is also a significant cluster of work relating to money laundering, presenting evidence that forthcoming issues with regards to these new digital products were identifiable far in advance of their eventual occurrence. In the period 2015 through 2018, we can observe the clear expansion of coverage across multiple research disciplines. The largest clusters surround that of Physica A and PLOS One, focusing on the technical aspects surrounding the underlying characteristics of cryptocurrency, while Finance Research Letters and Economics Letters focus on the financial and pricing implications. In the lower panel, we observe the research clusters for the period post-2018, identifying further expansion of research coverage along with several distinct areas of research.

\section{Conclusions}

Cryptocurrencies are a novel, and sometimes controversial financial instrument. Regardless of whether one believes them to be a passing fad, the future of money or somewhere in between, they have emerged as one of the most interesting and discussed financial assets of the last decade. We find here that these assets have had greatly increased research activity focused on them over the last two years. This research however is characterised by being rather fragmented. It is fragmented in a significant sense across products and broad areas. While islands of research do connect they do so in very limited ways. There are parallel, mostly non-overlapping research initiatives drawing inspiration form the technical and the economic literature but limited "interdisciplinary" research. It is our hope that this handbook goes some way to providing an overview of the areas of research and will spark greater cooperation

\section{References}

Akhtaruzzaman, M., A. Sensoy, and S. Corbet (2019). The influence of bitcoin on portfolio diversification and design. Finance Research Letters Available online at: https://doi.org/10.1016/j.frl.2019.101344.

Akyildirim, E., S. Corbet, P. Katsiampa, N. Kellard, and A. Sensoy (2019). The development of bitcoin futures: Exploring the interactions between cryptocurrency derivatives. Finance Research Letters Available online at: https://doi.org/10.1016/j.frl.2019.0\%.00\%.

Akyildirim, E., S. Corbet, B. Lucey, A. Sensoy, and L. Yarovaya (2019). The relationship between implied volatility and cryptocurrency returns. Finance Research Letters.

Aria, M. and C. Cuccurullo (2017). bibliometrix: An r-tool for comprehensive science mapping analysis. Journal of Informetrics 11(4), 959-975.

Bouri, E., P. Molnár, G. Azzi, D. Roubaud, and L. I. Hagfors (2017). On the hedge and safe haven properties of bitcoin: Is it really more than a diversifier? Finance Research Letters 20, 192-198.

Cheah, E.-T. and J. Fry (2015). Speculative bubbles in bitcoin markets? an empirical investigation into the fundamental value of bitcoin. Economics Letters 130, 32-36. 
Chung, K. H. and R. A. Cox (1990). Patterns of productivity in the finance literature: a study of the bibliometric distributions. the Journal of Finance 45(1), 301-309.

Corbet, S., D. Cumming, B. Lucey, M. Peat, and S. Vigne (2019). The destabilising effects of cryptocurrency cybercriminality. Economics Letters.

Corbet, S., M. Dowling, X. Gao, S. Huang, B. Lucey, and S. A. Vigne (2019). An analysis of the intellectual structure of research on the financial economics of precious metals. Resources Policy 63, 101416.

Corbet, S., V. Eraslan, B. Lucey, and A. Sensoy (2019). The effectiveness of technical trading rules in cryptocurrency markets. Finance Research Letters 31, 32-37.

Corbet, S., C. Larkin, B. Lucey, A. Meegan, and L. Yarovaya (2020). Cryptocurrency reaction to FOMC announcements: Evidence of heterogeneity based on blockchain stack position. Journal of Financial Stability 46, 100706.

Corbet, S., B. Lucey, M. Peat, and S. Vigne (2018). Bitcoin futures-what use are they? Economics Letters 172, $23-27$.

Corbet, S., B. Lucey, A. Urquhart, and L. Yarovaya (2019). Cryptocurrencies as a financial asset: A systematic analysis. International Review of Financial Analysis 62, 182-199.

Corbet, S., B. Lucey, and L. Yarovya (2018). Datestamping the bitcoin and ethereum bubbles. Finance Research Letters 26(1), 81-88.

Corbet, S., A. Meegan, C. Larkin, B. Lucey, and L. Yarovaya (2018). Exploring the dynamic relationships between cryptocurrencies and other financial assets. Economics Letters 165, 28-34.

Danezis, G., A. Tsagkaris, F. Camin, V. Brusic, and C. Georgiou (2016). Food authentication: Techniques, trends emerging approaches. TrAC - Trends in Analytical Chemistry 85, 123-132.

Franceschet, M. (2010). A comparison of bibliometric indicators for computer science scholars and journals on web of science and google scholar. Scientometrics 83(1), 243-258. cited By 85.

Fry, J. (2018). Booms, busts and heavy-tails: The story of bitcoin and cryptocurrency markets? Economics Letters 171, 225-229.

Gandal, N., J. Hamrick, T. Moore, and T. Oberman (2018). Price manipulation in the bitcoin ecosystem. Journal of Monetary Economics 95, 86-96.

Griffins, J. and A. Shams (2018). Is bitcoin really un-tethered? Available at SSRN: https://ssrn.com/abstract=3195066 13 June 2018.

Harzing, A.-W. and S. Alakangas (2016). Google scholar, scopus and the web of science: a longitudinal and crossdisciplinary comparison. Scientometrics 106(2), 787-804.

He, Q., G. Wang, L. Luo, Q. Shi, J. Xie, and X. Meng (2017). Mapping the managerial areas of building information modeling (bim) using scientometric analysis. International Journal of Project Management 35(4), 670-685.

Jappe, A., D. Pithan, and T. Heinze (2018). Does bibliometric research confer legitimacy to research assessment practice? a sociological study of reputational control, 1972-2016. PloS one 13(6), e0199031.

Katsiampa, P., S. Corbet, and B. Lucey (2019a). High frequency volatility co-movements in cryptocurrency markets. Journal of International Financial Markets, Institutions and Money 62, 35-52. 
Katsiampa, P., S. Corbet, and B. Lucey (2019b). Volatility spillover effects in leading cryptocurrencies: A bekkmgarch analysis. Finance Research Letters 29, 68-74.

Konur, O. (2011). The scientometric evaluation of the research on the algae and bio-energy. Applied Energy 88(10), $3532-3540$.

Konur, O. (2012a). The evaluation of the research on the biodiesel: A scientometric approach. Energy Education Science and Technology Part A: Energy Science and Research 28(2), 1003-1014.

Konur, O. (2012b). The evaluation of the research on the biohydrogen: A scientometric approach. Energy Education Science and Technology Part A: Energy Science and Research 29(1), 323-338.

Kosnik, L.-R. (2018). A survey of jel codes: What do they mean and are they used consistently? Journal of economic surveys 32(1), 249-272.

Levine-Clark, M. and E. L. Gil (2008). A comparative citation analysis of web of science, scopus, and google scholar. Journal of Business 8 Finance Librarianship 14(1), 32-46.

Li, X., P. Jiang, T. Chen, X. Luo, and Q. Wen (2017). A survey on the security of blockchain systems. Future Generation Computer Systems.

Lowry, P., G. Moody, J. Gaskin, D. Galletta, S. Humpherys, J. Barlow, and D. Wilson (2013). Evaluating journal quality and the association for information systems senior scholars' journal basket via bibliometric measures: Do expert journal assessments add value? MIS Quarterly: Management Information Systems 37(4), 993-1012.

Michels, C. and U. Schmoch (2012). The growth of science and database coverage. Scientometrics 93(3), 831-846.

Mongeon, P. and A. Paul-Hus (2016a). The journal coverage of web of science and scopus: a comparative analysis. Scientometrics 106(1), 213-228. cited By 88.

Mongeon, P. and A. Paul-Hus (2016b). The journal coverage of web of science and scopus: a comparative analysis. Scientometrics 106(1), 213-228.

Nakamoto, S. (2009). Bitcoin: A peer-to-peer electronic cash system. Technical report, Manubot.

Olawumi, T. and D. Chan (2018). A scientometric review of global research on sustainability and sustainable development. Journal of Cleaner Production 183, 231-250.

Phillips, P. C., Y. Wu, and J. Yu (2011). Explosive behavior in the 1990's nasdaq: When did exuberance escalate asset values? International Economic Review 52(1), 201-226.

Rotolo, D., D. Hicks, and B. Martin (2015). What is an emerging technology? Research Policy 44(10), 1827-1843.

Ruaro, R. and Gubiani (2013). A scientometric assessment of 30 years of the index of biotic integrity in aquatic ecosystems: Applications and main flaws. Ecological Indicators 29, 105-110.

Sensoy, A. (2018). The inefficiency of bitcoin revisited: A high-frequency analysis with alternative currencies. Finance Research Letters.

Serenko, A., T. Hardie, N. Bontis, L. Booker, and K. Sadeddin (2010). A scientometric analysis of knowledge management and intellectual capital academic literature (19942008). Journal of Knowledge Management 14(1), $3-23$. 
Tschorsch, F. and B. Scheuermann (2016). Bitcoin and beyond: A technical survey on decentralized digital currencies. IEEE Communications Surveys \& Tutorials 18(3), 2084-2123.

Urquhart, A. (2016a). The inefficiency of bitcoin. Economics Letters 148, 80-82.

Urquhart, A. (2016b). The inefficiency of bitcoin. Economics Letters 148, 80-82.

Vieira, E. and J. Gomes (2009). A comparison of scopus and web of science for a typical university. Scientometrics $81(2)$, 587-600. cited By 88.

Waltman, L. (2016). A review of the literature on citation impact indicators. Journal of informetrics 10(2), 365-391.

Zhao, X. (2017). A scientometric review of global bim research: Analysis and visualization. Automation in Construction $80,37-47$. 
Figure 1: Number of observations based on research designation

a) Broad Area-Based Research

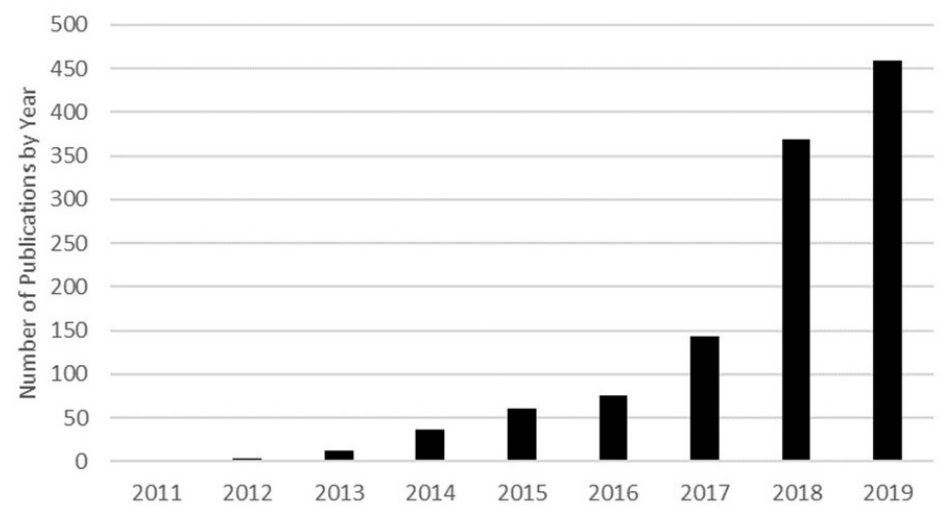

b) Narrow Product-Based Research

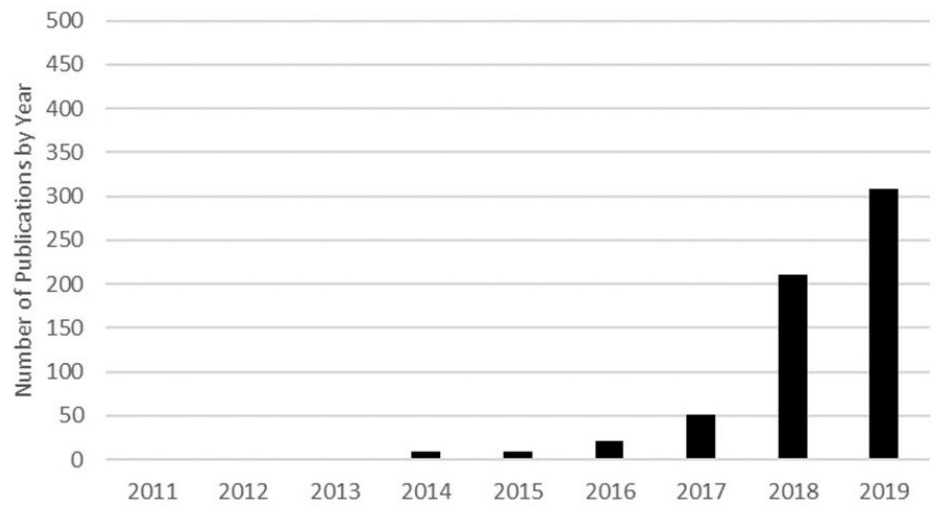

Note: The above data was compiled as of November 2019. 
Figure 2: Co-authorship patterns across countries

a) Narrow Product-Based Research



b) Broad Area-Based Research

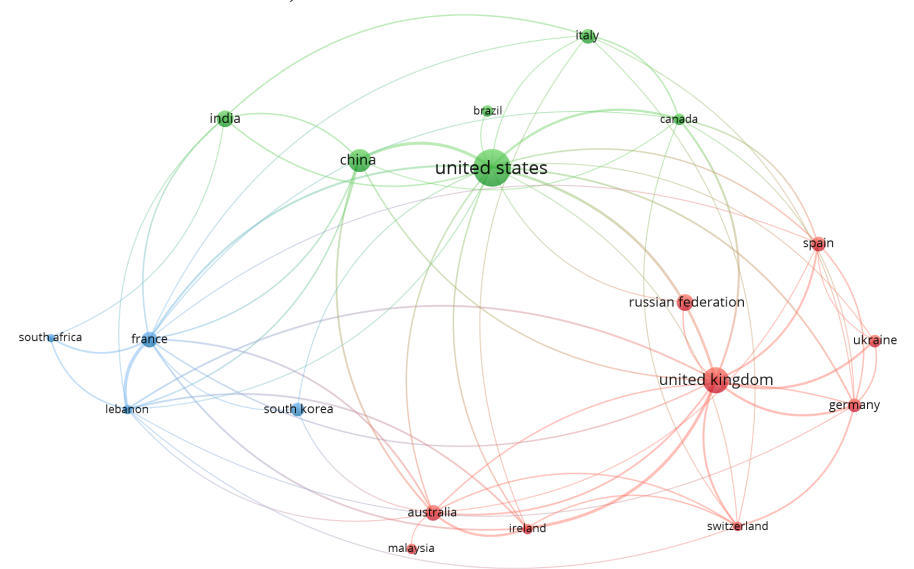

c) Combination of Research Types

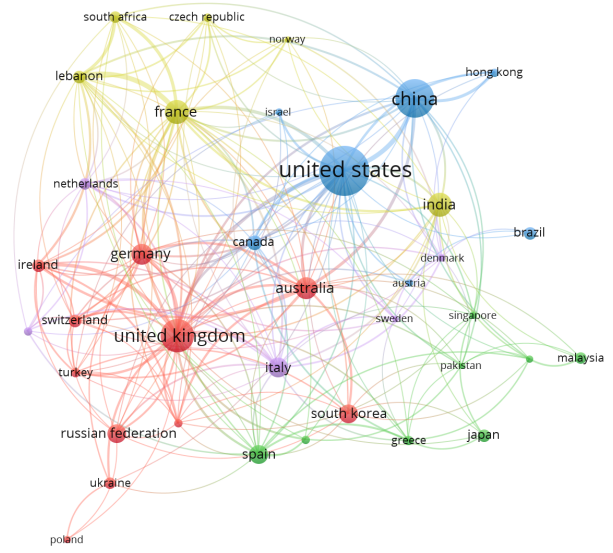

Note: The above figure we see the coauthorship as analysed using clusters of the countries represented in the field. The top panel represents all research based on narrow product-based research (that is Bitcoin for example). The middle panel represents broad area-based research. The lower panel represents all analysed research. The above figure is prepared using VOSviewer which is a software tool for constructing and vistallising bibliometric networks. The above data was compiled as of November 2019. 
Figure 3: Co-authorship patterns across authors

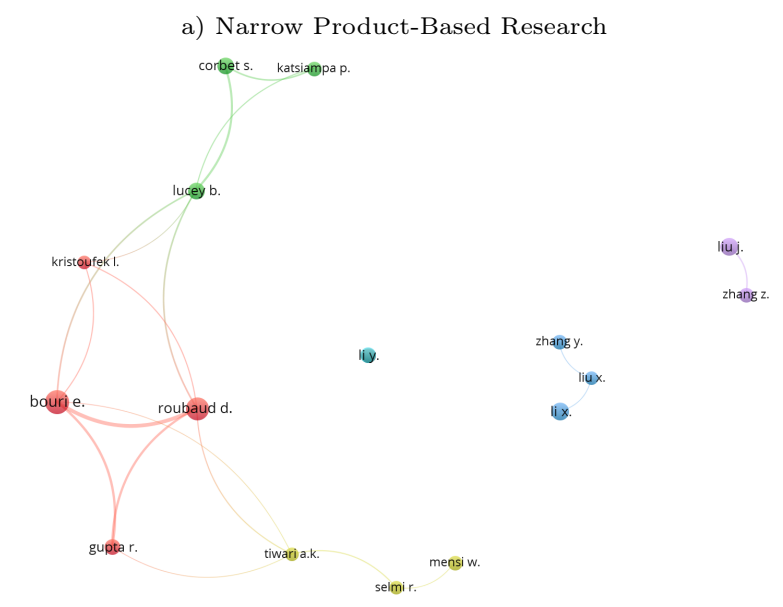

b) Broad Area-Based Research
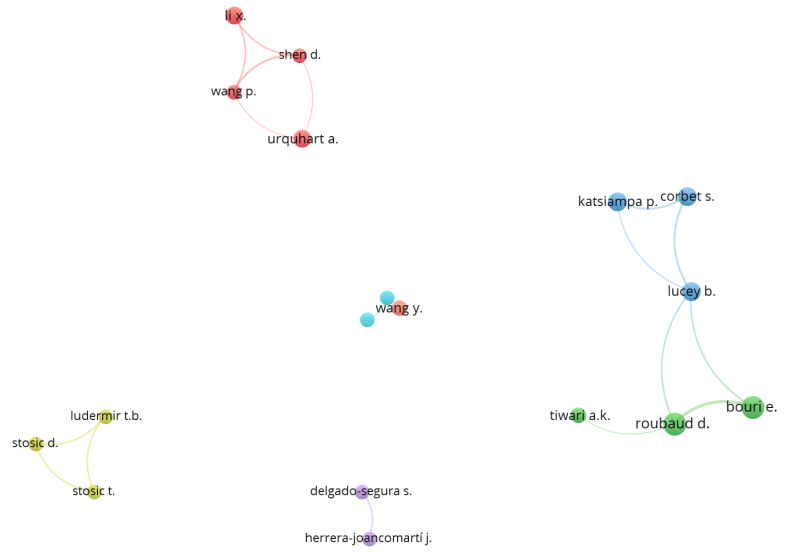

c) Combination of Research Types

liuj. zhangz.

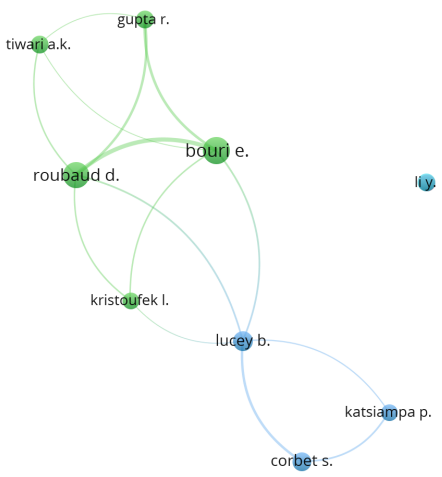

wang $y$.

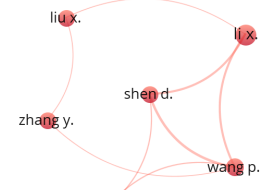

urqueart a.

Note: The above figure we see the coauthorship as analysed using clusters of the authors represented in the field. The top panel represents all research based on narrow product-based research (that is Bitcoin for example). The middle panel represents broad area-based research. The lower panel represents all analysed research. The above figure is prepared using VOSviewer which is a software tool for constructing and visualising bibliometric networks. The above data was compiled as of November 2019. 
Figure 4: Citation pattern across sources

a) Narrow Product-Based Research

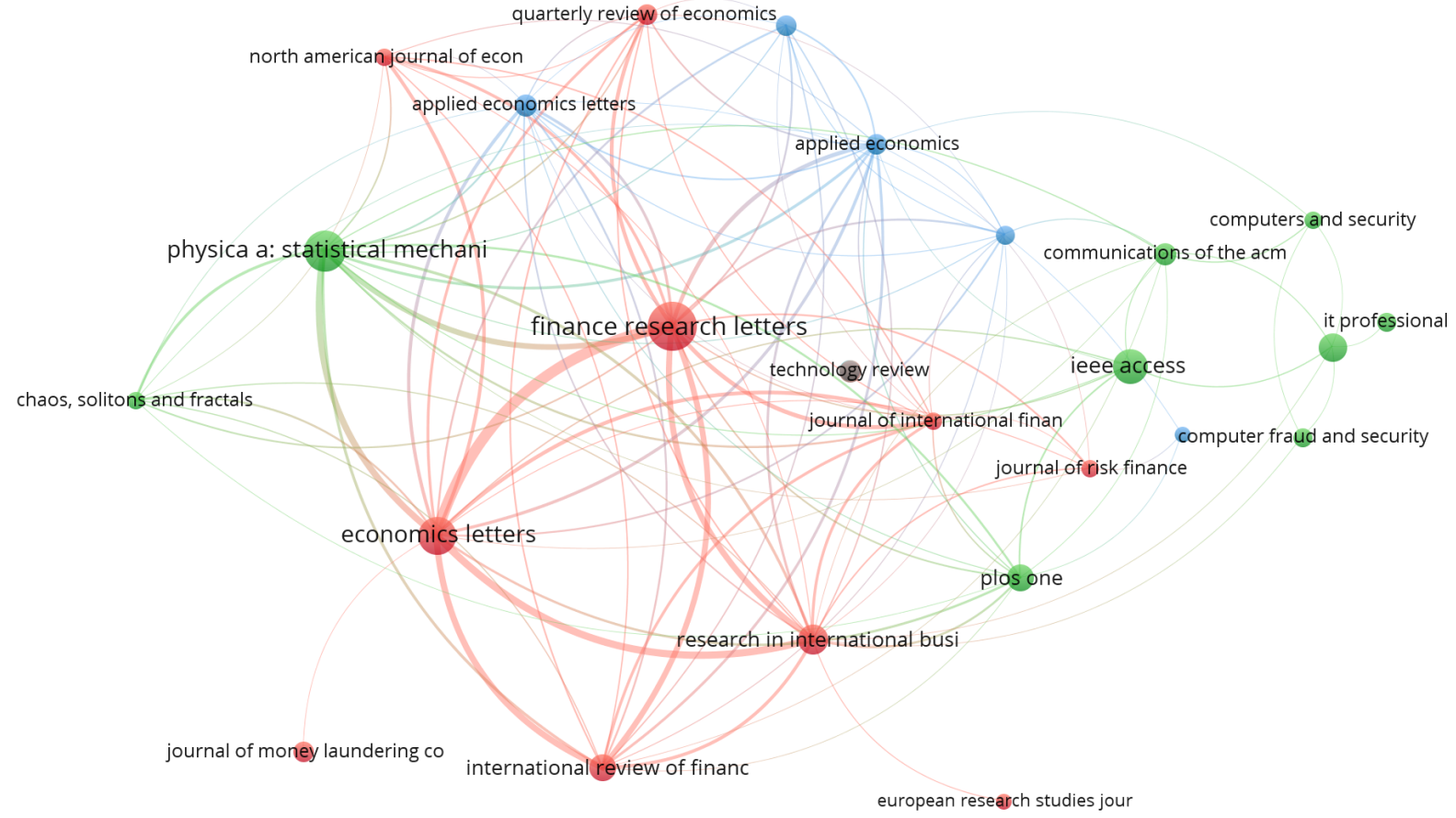

b) Broad Area-Based Research

technology review

journal of legal, ethical and



19

Note: A citation network is a graphical representation of how often elements of the graph cite each other. We show this in the above figure for sources, and the table showing cluster memberships are shown above. The top panel represents all research based on narrow product-based research (that is Bitcoin for example). The lower panel represents broad area-based research. The above figures are prepared using VOSviewer which is a software tool for constructing and visualising bibliometric networks. The above data was compiled as of November 2019. 
Figure 5: Citation pattern across countries

a) Narrow Product-Based Research



b) Broad Area-Based Research

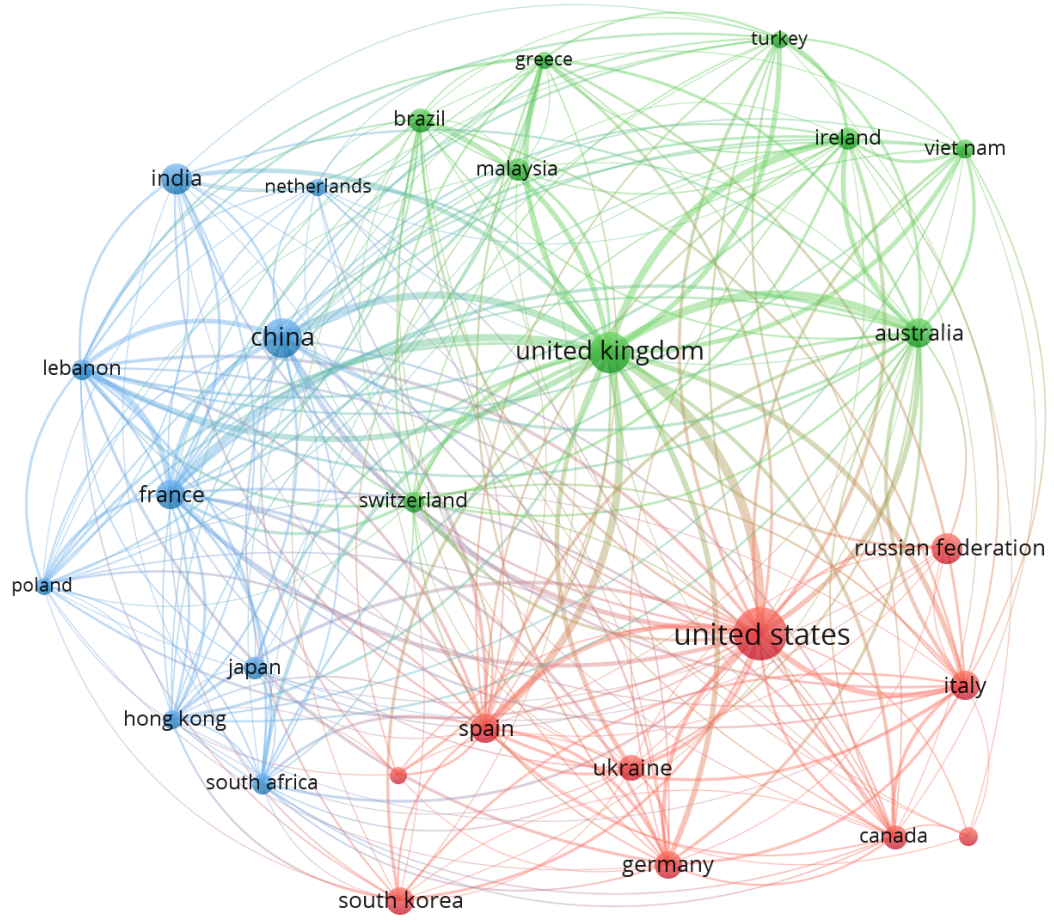

20

Note: A citation network is a graphical representation of how often elements of the graph cite each other. We show this in the above figure for sources, and the table showing cluster memberships are shown above. The top panel represents all research based on narrow product-based research (that is Bitcoin for example). The lower panel represents broad area-based research. The above figures are prepared using VOSviewer which is a software tool for constructing and visualising bibliometric networks. The above data was compiled as of November 2019. 
Figure 6: Heatmap presenting citation pattern across countries (Full Sample)

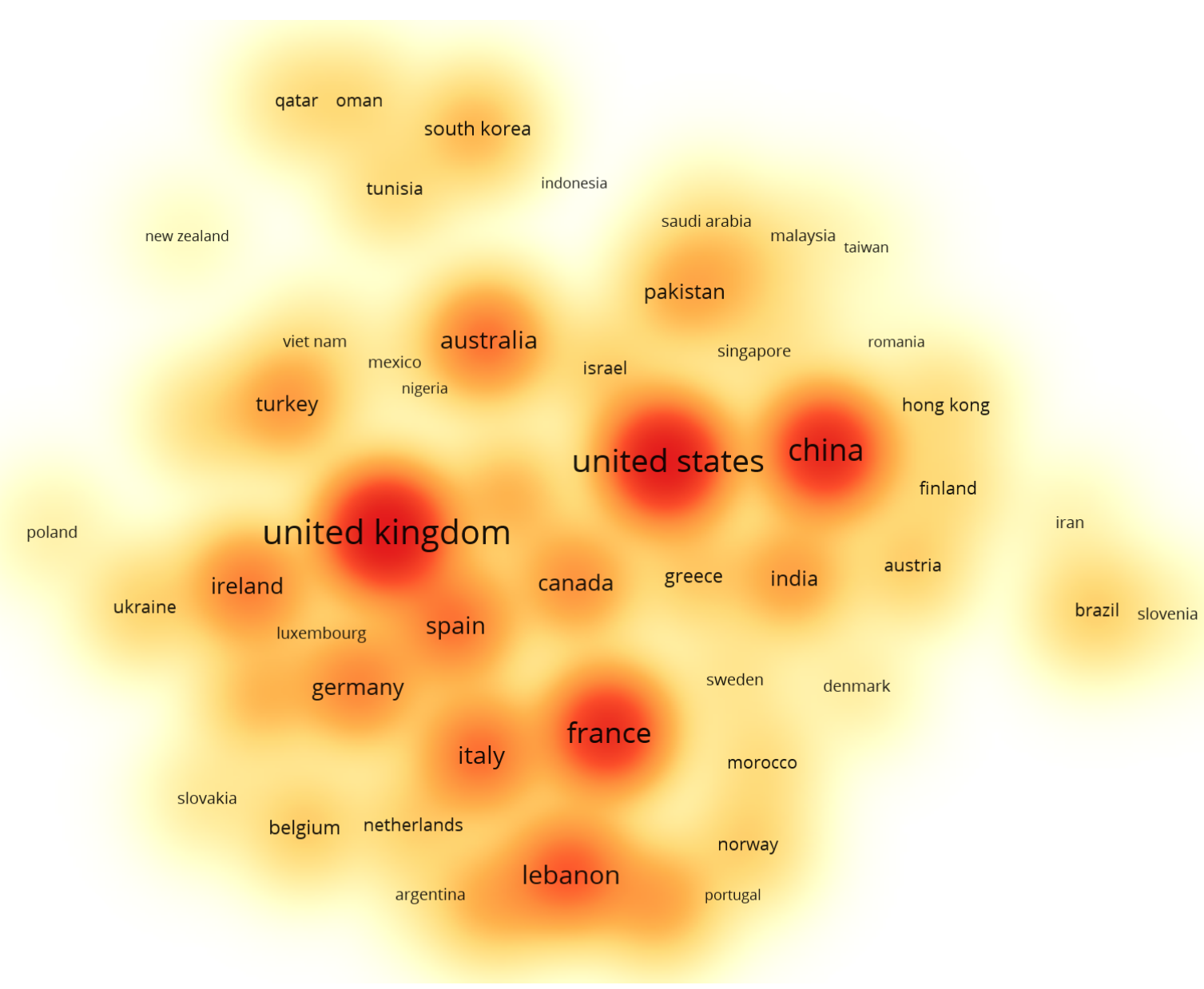

Note: A citation network is a graphical representation of how often elements of the graph cite each other. We show this in the above figure for sources, and the table showing cluster memberships are shown above. The above figure is prepared using VOSviewer which is a software tool for constructing and visualising bibliometric networks. The above data was compiled as of November 2019. 


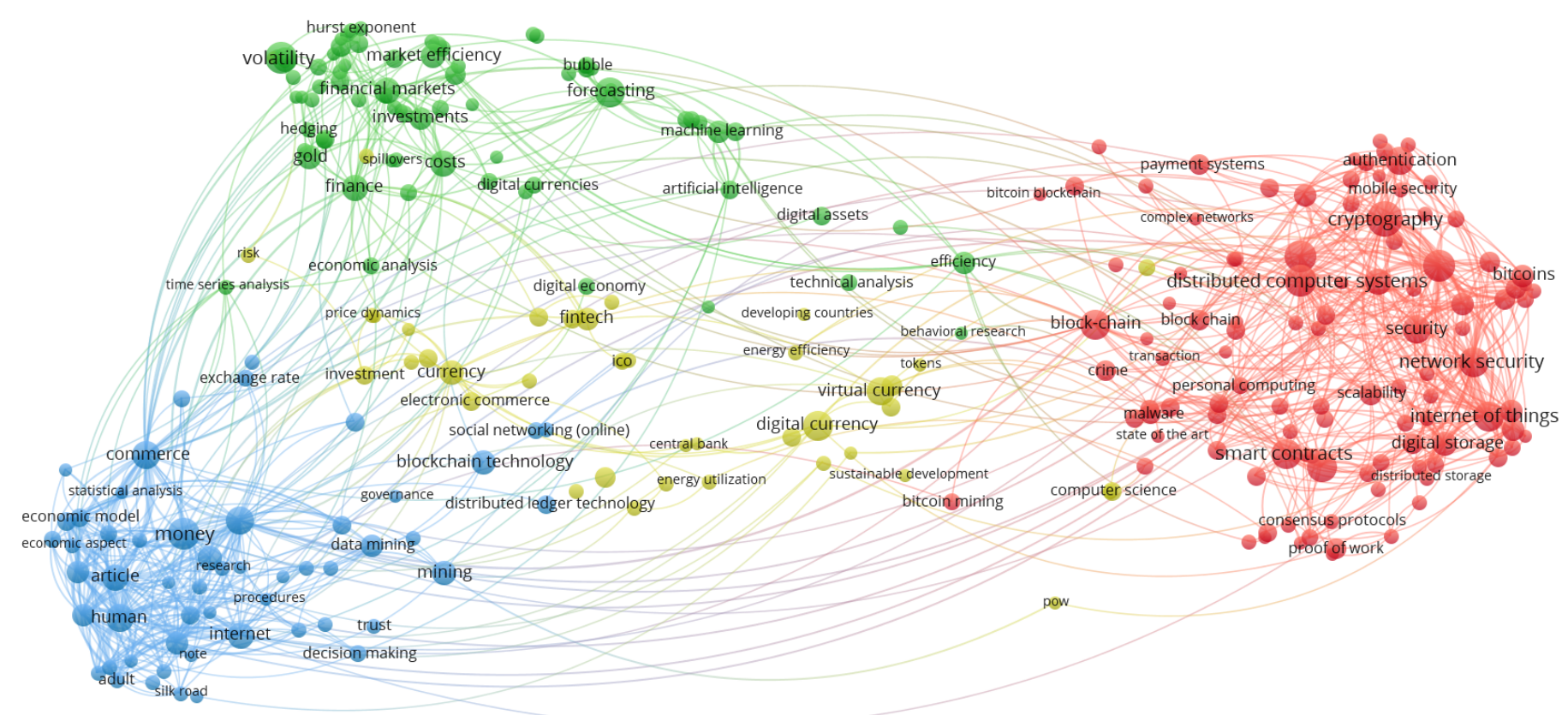

Note: The above figure is prepared using VOSviewer which is a software tool for constructing and visualising bibliometric networks. The above data was compiled as of November 2019 
Figure 8: Abstract Keyword Cooccurance

a) Narrow Product-Based Research



b) Broad Area-Based Research

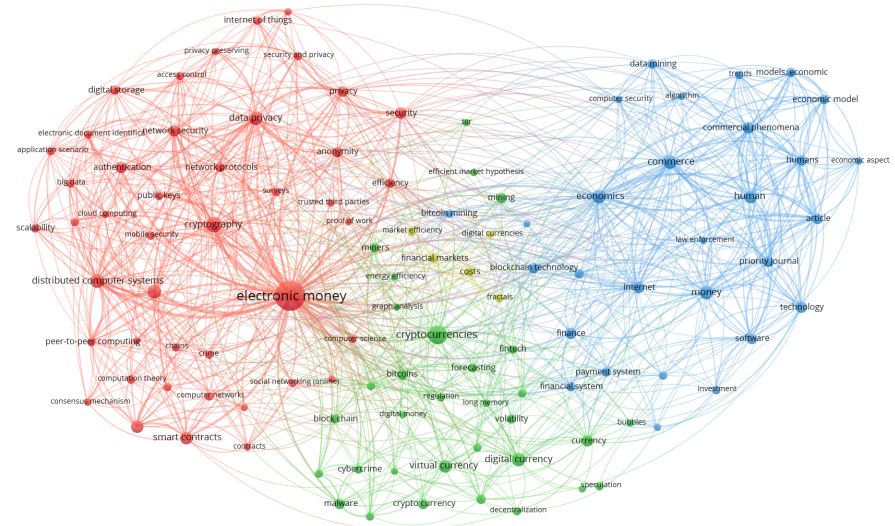

c) Combination of Research Types

$$
\text { atgen eiver }
$$

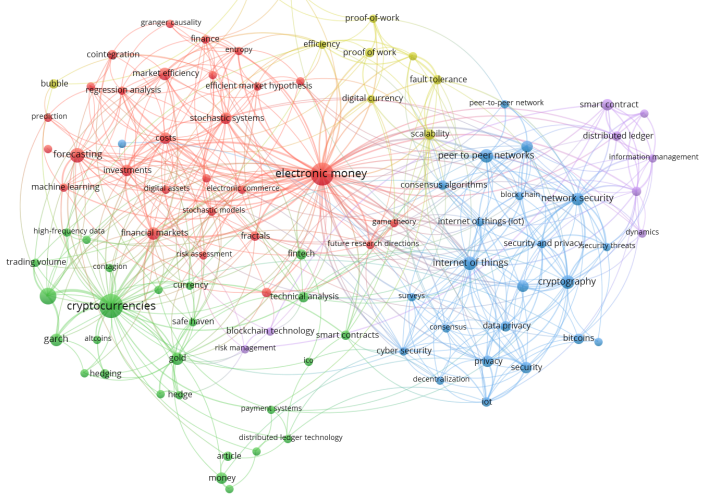

Note: In the above figure we create networks of terms. In the case of material exported from Scopus it is possible to use some or all of the Author Keywords, the publisher created Index Keywords, and the Abstract. We show this in the above figure for sources, and the table showing cluster memberships are shown above. The top panel represents all research based on narrow product-based research (that is Bitcoin for example). The middle panel represents broad area-based research. The lower panel represents all analysed research. The above figure is prepared using VOSviewer which is a software tool for constructing and visualising bibliometric networks. The above data was compiled as of November 2019. 
Figure 9: Overall Keyword Cooccurance

a) Pre-2015 Keyword Cooccurance

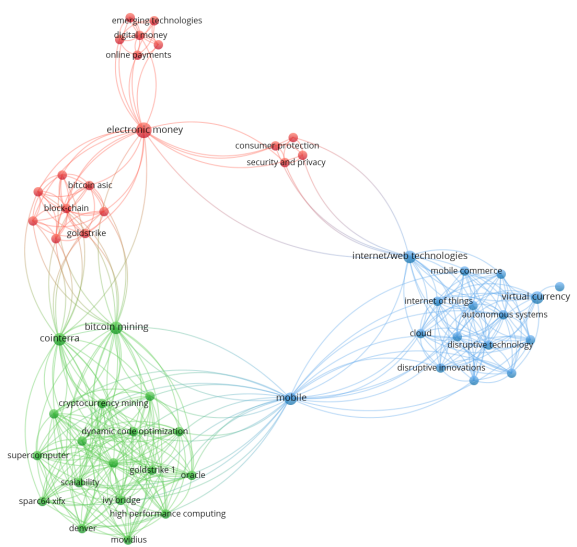

b) Keyword Cooccurance between 2016 and 2018

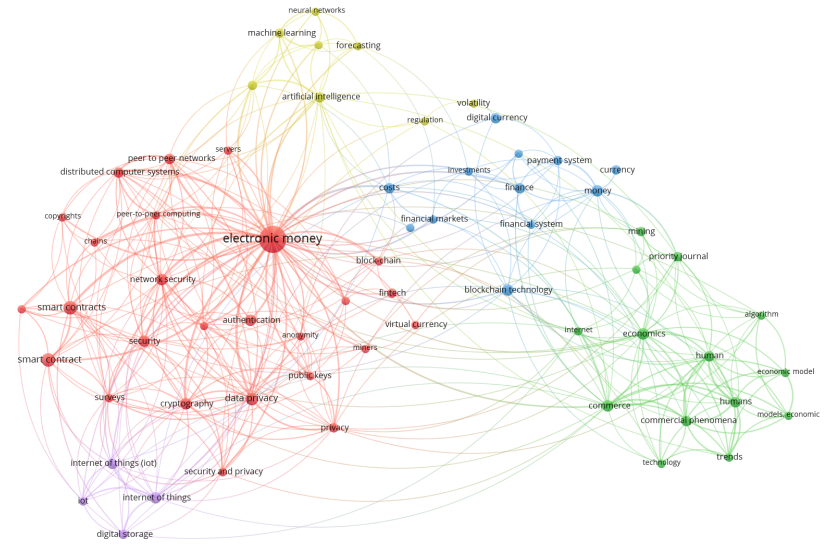

c) Post-2018 Keyword Cooccurance

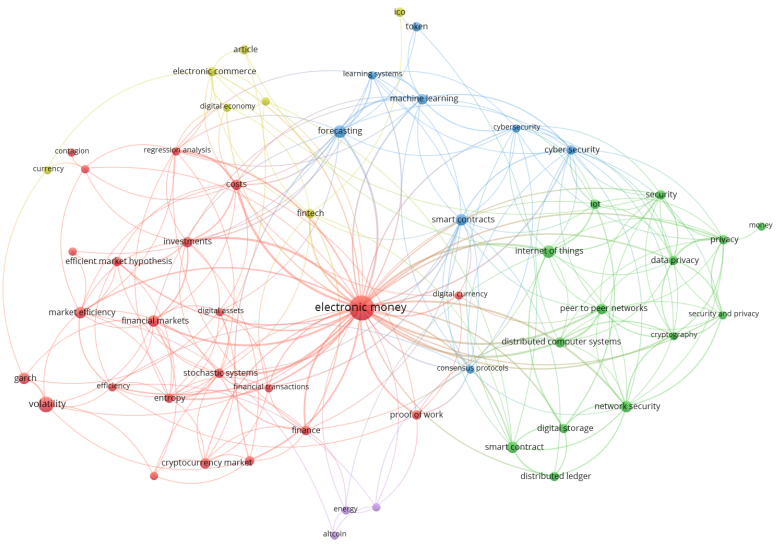

Note: In the above figure we create networks of terms. In the case of material exported from Scopus it is possible to use some or all of the Author Keywords, the publisher created Index Keywords, and the Abstract. We show this in the above figure for sources, and the table showing cluster memberships are shown above. The top panel represents the keyword cooccurance for the period before 1 January 2015. The middle panel represents the keyword cooccurance for the period between 1 January 2015 and 31 December 2018. The lower panel represents the keyword cooccurance for the period after 1 January 2019. The above figure is prepared using VOSviewe24which is a software tool for constructing and visualising bibliometric networks. The above data was compiled as of November 2019. 
Figure 10: Bibliometric Coupling

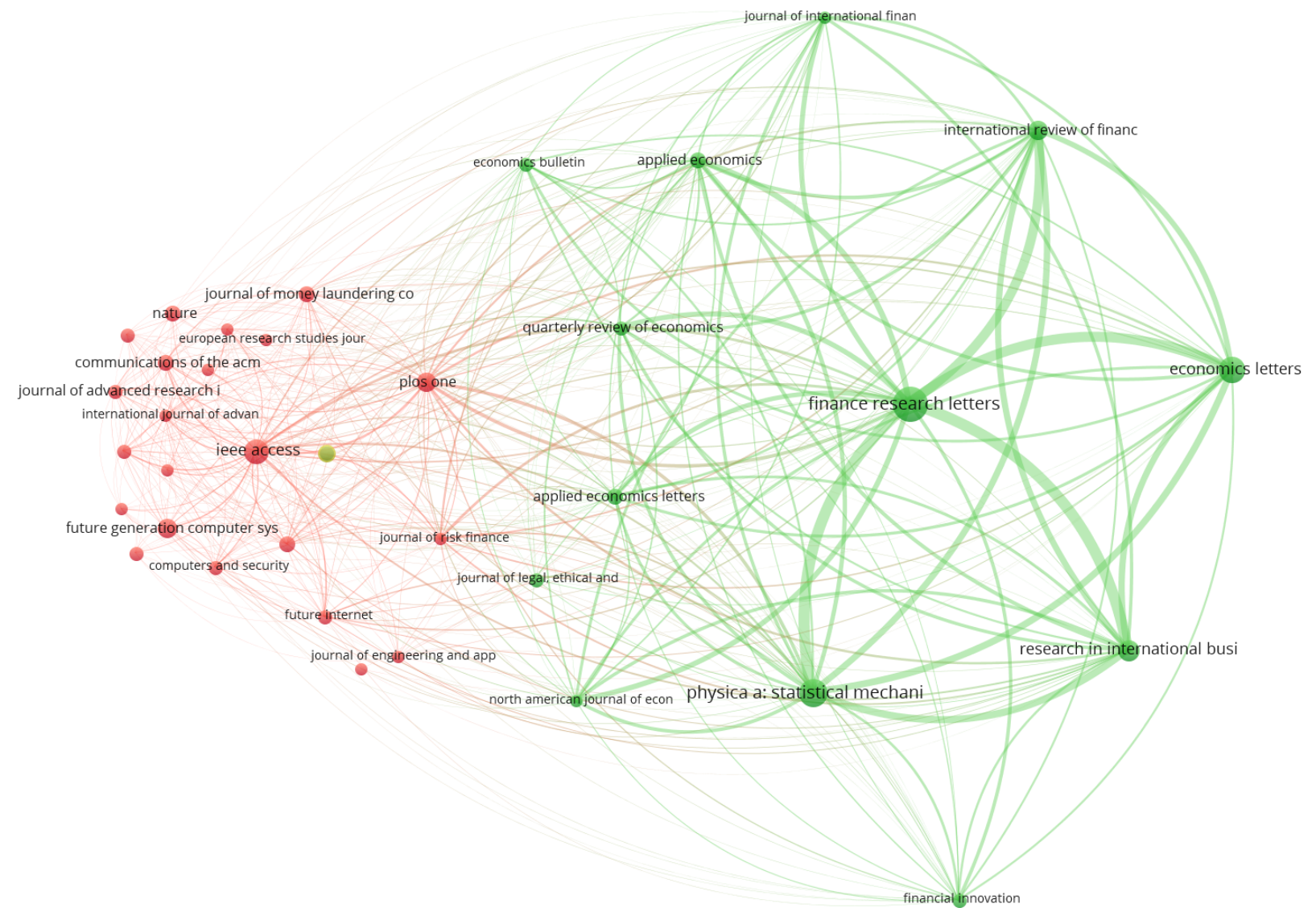

Note: The above figure presents a bibliometric coupling for sources. The above figure is prepared using VOSviewer which is a software tool for constructing and visualising bibliometric networks. The above data was compiled as of November 2019 . 
Figure 11: Bibliometric Coupling by Cited Sources



Note: The above figure presents a bibliometric coupling for sources. The above figure is prepared using VOSviewer which is a software tool for constructing and visualising bibliometric networks. The above data was compiled as of November 2019. 
Figure 12: Bibliometric cited sources over time

a) Pre-2015 Research Citations

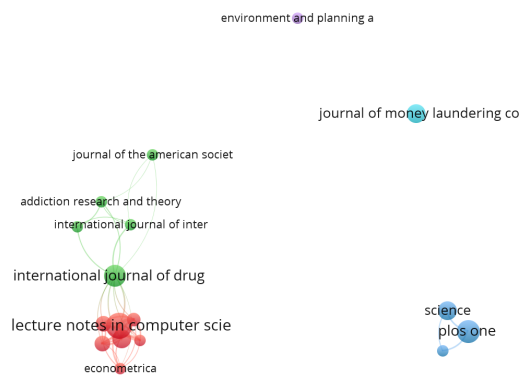

b) Research Citations 2015 through 2018



c) Post-2018 Research Citations

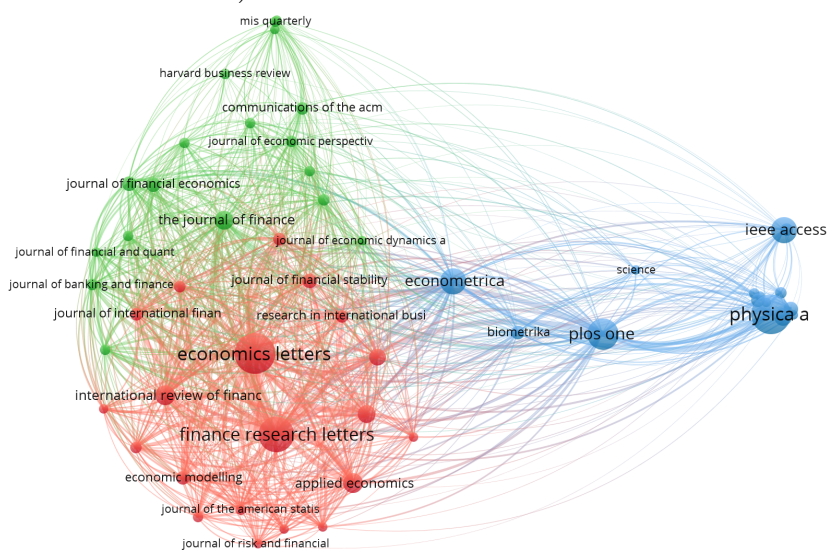

Note: The above figure presents a bibliometric coupling for sources over time. The top panel represents the bibliometric cited sources for the period before 1 January 2015. The middle panel represents the bibliometric cited sources for the period between 1 January 2015 and 31 December 2018. The lower panel represents the bibliometric cited sources for the period after 1 January 2019. The above figure is prepared using VOSviewer which is a software tool for constructing and visualising bibliometric networks. The above data was compiled as of November 2019. 
Table 1: Descriptive Statistics based on the selected dataset

\begin{tabular}{llll}
\hline \hline Measure & By product & By topic & Total \\
\hline Documents & 1,169 & 535 & 1,704 \\
Sources (Journals, Books, etc) & 521 & 323 & 844 \\
Citations & 10,773 & 3,739 & 14,512 \\
Average citations per document & 9.22 & 6.99 & 8.52 \\
Authors & 2,326 & 1,416 & 3,742 \\
Authors of single authored documents & 274 & 137 & 411 \\
Authors of multi authored documents & 2,052 & 1,279 & 3,331 \\
Documents per author & 0.50 & 0.38 & 0.46 \\
Authors per document & 1.99 & 2.65 & 2.20 \\
\hline \hline
\end{tabular}

Note: The above data was compiled as of November 2019.

Table 2: Top citation sources by author

\begin{tabular}{|c|c|c|c|c|c|c|c|}
\hline \multicolumn{4}{|c|}{ Narrow Product-Based Research } & \multicolumn{4}{|c|}{ Broad Area-Based Research } \\
\hline Rank & Author & Articles & Fractional & Rank & Author & Articles & Fractional \\
\hline 1 & Bouri E. & 12 & 9.9 & 1 & Bouri E. & 26 & 15.3 \\
\hline 2 & Roubaud D. & 12 & 9.9 & 2 & Roubaud D. & 23 & 17.2 \\
\hline 4 & Katsiampa P. & 8 & 10.6 & 4 & Liu J. & 12 & 0.4 \\
\hline 5 & Lucey B. & 8 & 6.9 & 5 & Lucey B. & 11 & 16.6 \\
\hline 6 & Li X. & 7 & 7.7 & 6 & Corbet S. & 11 & 17.6 \\
\hline 9 & Tiwari A.K. & 5 & 0.5 & 8 & Katsiampa P. & 8 & 16.8 \\
\hline 10 & Wang Y. & 5 & 4.3 & 9 & Mensi W. & 8 & 13.5 \\
\hline 11 & Choo K.-K.R. & 4 & 1.9 & 10 & Urquhart A. & 8 & 19.6 \\
\hline 12 & Delgado-Segura S. & 4 & 1.3 & 11 & Kristoufek L. & 7 & 11.3 \\
\hline 13 & Herrera-Joancomartí J. & 4 & 1.3 & 12 & Liu X. & 7 & 1.3 \\
\hline 14 & $\mathrm{Li} \mathrm{H.}$ & 4 & 6.3 & 13 & Luther W.J. & 7 & 4.3 \\
\hline $20-$ & Stosic D./Stosic T. & 4 & 1.6 & 19 & Herrera-Joancomartí J. & 6 & 0.0 \\
\hline
\end{tabular}

Note: The above data was compiled as of November 2019. 
Table 3: Top citation sources by country

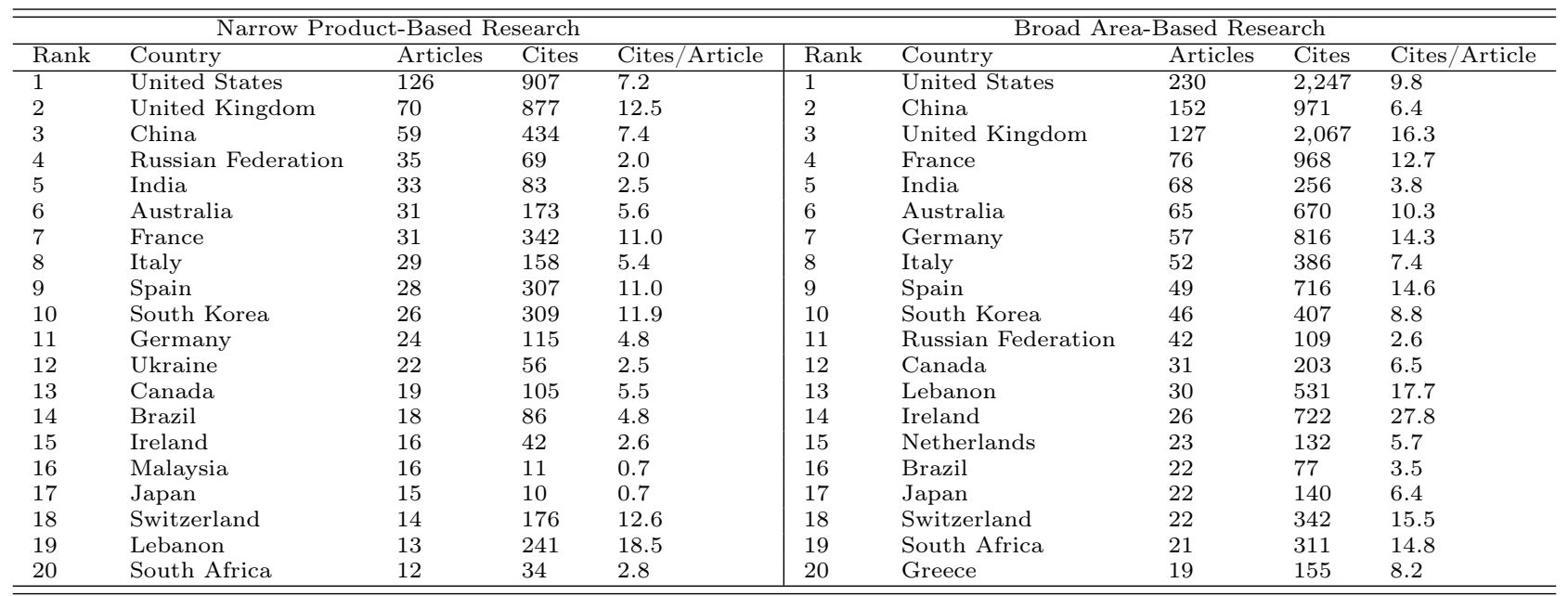

Note: The above data was compiled as of November 2019.

Table 4: Top ten journals as defined by both broad and narrow product-based research

\begin{tabular}{|c|c|c|c|c|c|c|c|}
\hline \multicolumn{4}{|c|}{ Narrow Product-Based Research } & \multicolumn{4}{|c|}{ Broad Area-Based Research } \\
\hline Rank & Source & Documents & Citations & Rank & Source & Documents & Citations \\
\hline 1 & $\begin{array}{l}\text { Finance Research Let- } \\
\text { ters }\end{array}$ & 66 & 1,005 & 1 & $\begin{array}{l}\text { Finance Research Let- } \\
\text { ters }\end{array}$ & 42 & 287 \\
\hline 2 & Economics Letters & 38 & 1,380 & 2 & Economics Letters & 20 & 583 \\
\hline 3 & IEEE Access & 29 & 273 & 3 & IEEE Access & 13 & 161 \\
\hline 4 & $\begin{array}{l}\text { Future Generation Com- } \\
\text { puter Systems }\end{array}$ & 19 & 227 & 4 & Applied Economics & 7 & 75 \\
\hline 5 & $\begin{array}{l}\text { International Review of } \\
\text { Financial Analysis }\end{array}$ & 17 & 192 & 5 & $\begin{array}{l}\text { Applied Economics Let- } \\
\text { ters }\end{array}$ & 7 & 13 \\
\hline 6 & $\begin{array}{l}\text { Applied Economics Let- } \\
\text { ters }\end{array}$ & 10 & 167 & 6 & $\begin{array}{l}\text { Computer Law and Se- } \\
\text { curity Review }\end{array}$ & 6 & 20 \\
\hline 7 & Applied Economics & 9 & 242 & 7 & $\begin{array}{l}\text { Future Generation Com- } \\
\text { puter Systems }\end{array}$ & 6 & 97 \\
\hline 8 & $\begin{array}{l}\text { Computer Fraud and Se- } \\
\text { curity }\end{array}$ & 7 & 62 & 8 & $\begin{array}{l}\text { Communications of the } \\
\text { ACM }\end{array}$ & 5 & 109 \\
\hline 9 & Financial Innovation & 7 & 55 & 9 & $\begin{array}{l}\text { Electronic Commerce } \\
\text { Research and Applica- } \\
\text { tions }\end{array}$ & 4 & 19 \\
\hline 10 & Future Internet & 7 & 185 & 10 & Business Horizons & 3 & 14 \\
\hline
\end{tabular}

Note: The above data was compiled as of November 2019. 
Table 5: Top ten articles as defined by both broad and narrow product-based research

\begin{tabular}{|c|c|}
\hline \multicolumn{2}{|r|}{ Narrow Product-Based Research } \\
\hline 1 & $\begin{array}{l}\text { Tschorsch, F. and Scheuermann, B., 2016. Bitcoin and beyond: A technical survey on de- } \\
\text { centralized digital currencies. IEEE Communications Surveys \& Tutorials, 18(3), pp.2084- } \\
2123 \text {. }\end{array}$ \\
\hline 2 & $\begin{array}{l}\text { Yli-Huumo, J., Ko, D., Choi, S., Park, S. and Smolander, K., 2016. Where is current } \\
\text { research on blockchain technology? - a systematic review. PloS one, 11(10), p.e0163477. }\end{array}$ \\
\hline 3 & $\begin{array}{l}\text { Böhme, R., Christin, N., Edelman, B. and Moore, T., 2015. Bitcoin: Economics, technol- } \\
\text { ogy, and governance. Journal of Economic Perspectives, 29(2), pp.213-38. }\end{array}$ \\
\hline 4 & Urquhart, A., 2016. The inefficiency of Bitcoin. Economics Letters, 148, pp.80-82. \\
\hline 5 & $\begin{array}{l}\text { Cheah, E.T. and Fry, J., 2015. Speculative bubbles in Bitcoin markets? An empirical } \\
\text { investigation into the fundamental value of Bitcoin. Economics Letters, 130, pp.32-36. }\end{array}$ \\
\hline 6 & $\begin{array}{l}\text { Dyhrberg, A.H., 2016. Bitcoin, gold and the dollar-A GARCH volatility analysis. Finance } \\
\text { Research Letters, 16, pp.85-92. }\end{array}$ \\
\hline 7 & $\begin{array}{l}\text { Khan, M.A. and Salah, K., 2018. IoT security: Review, blockchain solutions, and open } \\
\text { challenges. Future Generation Computer Systems, } 82 \text {, pp.395-411. }\end{array}$ \\
\hline 8 & $\begin{array}{l}\text { Kristoufek, L., 2015. What are the main drivers of the Bitcoin price? Evidence from } \\
\text { wavelet coherence analysis. PloS one, } 10(4) \text {, p.e0123923. }\end{array}$ \\
\hline 9 & $\begin{array}{l}\text { Dwyer, G.P., 2015. The economics of Bitcoin and similar private digital currencies. Journal } \\
\text { of Financial Stability, 17, pp.81-91. }\end{array}$ \\
\hline 10 & $\begin{array}{l}\text { Katsiampa, P., 2017. Volatility estimation for Bitcoin: A comparison of GARCH models. } \\
\text { Economics Letters, 158, pp.3-6. }\end{array}$ \\
\hline \multicolumn{2}{|r|}{ Broad Area-Based Research } \\
\hline 1 & $\begin{array}{l}\text { Li, X., Jiang, P., Chen, T., Luo, X. and Wen, Q., 2017. A survey on the security of } \\
\text { blockchain systems. Future Generation Computer Systems. }\end{array}$ \\
\hline 2 & $\begin{array}{l}\text { Zheng, Z., Xie, S., Dai, H.N., Chen, X. and Wang, H., 2018. Blockchain challenges and } \\
\text { opportunities: A survey. International Journal of Web and Grid Services, 14(4), pp.352- } \\
375 \text {. }\end{array}$ \\
\hline 3 & $\begin{array}{l}\text { Fernández-Caramés, T.M. and Fraga-Lamas, P., 2018. A Review on the Use of Blockchain } \\
\text { for the Internet of Things. IEEE Access, 6, pp.32979-33001. }\end{array}$ \\
\hline 4 & $\begin{array}{l}\text { Fry, J. and Cheah, E.T., 2016. Negative bubbles and shocks in cryptocurrency markets. } \\
\text { International Review of Financial Analysis, } 47 \text {, pp.343-352. }\end{array}$ \\
\hline 5 & $\begin{array}{l}\text { Bouri, E., Molnár, P., Azzi, G., Roubaud, D. and Hagfors, L.I., 2017. On the hedge and } \\
\text { safe haven properties of Bitcoin: Is it really more than a diversifier?. Finance Research } \\
\text { Letters, 20, pp.192-198. }\end{array}$ \\
\hline 6 & $\begin{array}{l}\text { Garcia, D., Tessone, C.J., Mavrodiev, P. and Perony, N., 2014. The digital traces of } \\
\text { bubbles: feedback cycles between socio-economic signals in the Bitcoin economy. Journal } \\
\text { of the Royal Society Interface, } 11(99), \text { p.20140623. }\end{array}$ \\
\hline 7 & $\begin{array}{l}\text { Phillip, A., Chan, J.S. and Peiris, S., 2018. A new look at Cryptocurrencies. Economics } \\
\text { Letters, 163, pp.6-9. }\end{array}$ \\
\hline 8 & $\begin{array}{l}\text { Kim, Y.B., Kim, J.G., Kim, W., Im, J.H., Kim, T.H., Kang, S.J. and Kim, C.H., } 2016 . \\
\text { Predicting fluctuations in cryptocurrency transactions based on user comments and replies. } \\
\text { PloS one, 11(8), p.e0161197. }\end{array}$ \\
\hline 9 & $\begin{array}{l}\text { Dai, J. and Vasarhelyi, M.A., 2017. Toward blockchain-based accounting and assurance. } \\
\text { Journal of Information Systems, 31(3), pp.5-21. }\end{array}$ \\
\hline 10 & $\begin{array}{l}\text { Kouicem, D.E., Bouabdallah, A. and Lakhlef, H., 2018. Internet of things security: A } \\
\text { top-down survey. Computer Networks, 141, pp.199-221. }\end{array}$ \\
\hline
\end{tabular}

Note: The above data was compiled as of November 2019. 
Table 6: Journals ranked by the number of overall cryptocurrency citations (both broad and narrow-based)

\begin{tabular}{|c|c|c|c|c|c|}
\hline Rank & Source & Citations & Rank & Source & Citations \\
\hline 1 & Economics Letters & 1,269 & 16 & Financial Cryptography \& Data Security & 120 \\
\hline 2 & Finance Research Letters & 977 & 17 & Review of Financial Studies & 119 \\
\hline 3 & Physica A & 706 & 18 & Journal of Econometrics & 97 \\
\hline 4 & $\begin{array}{l}\text { international Review of Financial Analy- } \\
\text { sis }\end{array}$ & 399 & 19 & Journal of Finance & 95 \\
\hline 5 & PLOS One & 338 & 20 & Quantitative Finance & 91 \\
\hline 6 & Applied Economics & 253 & 21 & American Economic Review & 84 \\
\hline 7 & Applied Economics Letters & 227 & 22 & Expert Systems with Applications & 73 \\
\hline 8 & Econometrica & 225 & 23 & Journal of Financial Stability & 73 \\
\hline 9 & IEEE Access & 204 & 24 & MIS Quarterly & 72 \\
\hline 10 & Communications of the ACM & 183 & 25 & Biometrika & 71 \\
\hline 11 & Journal of Finance & 168 & 26 & Nature & 71 \\
\hline 12 & Physical Review E & 154 & 27 & Journal of Economic Perspectives & 62 \\
\hline 13 & $\begin{array}{l}\text { Research in International Business \& Fi- } \\
\text { nance }\end{array}$ & 152 & 28 & Future Internet & 55 \\
\hline 14 & Journal of Financial Economics & 151 & 29 & Economic Modelling & 53 \\
\hline 15 & Energy Economics & 122 & 30 & $\begin{array}{l}\text { Journal of International Financial Mar- } \\
\text { kets, Institutions \& Money }\end{array}$ & 51 \\
\hline
\end{tabular}

Note: The above data was compiled as of November 2019. 